\title{
The Earliest Inhabitant
}

\section{Some of the Simplest of the Animal Forms that Go Back Into Geological Time}

\section{By William Butterfield}

NOTHING is more uncertain than the duration of Neological time: estimates of the earth's age, or of the length of certain periods therein, are tripled or divided by three overnight, as new data or a new method of attack upon the problem is developed. But whatever the number of millions of years which we attribute to the frame on which we live, for fully half this time, if not much more, it has been inhabited by the rhizopod family-the original member of which, indeed, was its first distinctively animal inhabitant. And so far as we are able to learn, this individual differed in form and action very little from his descendants still existing, and known under various more or less pronounceable names. It is true that the founder of the dynasty has left no record or other evidence which will enable us to form a definite notion of his personality, character, or physical appearance; yet we may arrive at a fairly accurate understanding of this individual by a study of his lineal descendants.

It is not at all difficult to meet a member of one certain branch: we find hundreds of him inhabiting every square inch of decaying vegetable infusion, not quite putrid, lying upon oozy mud that has for some time lain covered by fresh or salt water. This branch has a rat her pretty name, ameba, and is said to be much more highly organized than the first inhabitant. There is little to show that one group of the rhizopod family is more advanced than another, however all are extremely simple in everything that makes up their bodies.

It would be difficult to say exactly what is the form of an ameba's body. It frequently has the appearance of a small, rounded mass, like a drop of water but whatever the form may be, it is always unstable, changing every minute. It is amon the simplest organisms in all creation-a mere particle of living matter. Its body is like a drop of thin, almost trans. parent, mucilage, with. out head, trunk, limbs,

envelope, mouth, stomach, or any appreciable organization whatever. The amount of matter which forms it is so small (a mere twentieth of an inch in length) that often its transparency is such as to enable the eye to see it only by means of a careful arrangement of the light.

Yet this semi-transparent drop of mucilage-like substance-which we show in the drawing at 3 and $3 \mathrm{a}-$ is endowed with life and a power of motion. It projects from its body root-like processes-which we show in the second drawing-at times simple, sometimes branched. These are the feet, upon which the animal moves, or the hands, with which at times it obtains its food. Their appearance is different in the several renera. Any projection, having appeared and remained for a short time, will be seen to reenter the common mass, with which it hecomes completely reincorporated. When extended, if thiey come in contact they coalesce running together like streams of water and often form ing thin, lace-like structures.

The body mass is sticky, like the mucilage to which we have already compared it, and filled with minute granules which are seen to be in constant motion, forming currents circulating within the body and its projections. Smaller animals and vegetable organisms, coming in contact with any part of ameba, are attached to it and held by this viscid substance. The food particle thus sinks into the mass, if this be sufficiently large, and is literally engulfed by it; if, however, it be caugh by too small a projection to effect this result, the anima flows more of its substance into the region in question and finally succeeds in absorbing the other particle. After digestion is completed ameba disposes of the effete matter by simply flowing away from it.

Reproduction of species is a process quite as simple as that of maintaining life. All that is necessary is for the individual to separate into two or even more portions, each representing a somewhat smaller but none the less complete animal.

By investigating in this way the living forms of rhizopods we can arrive at a pretty fair understanding of the earth's first inhabitant. We may be sure that he could not have existed in a less primitive form, fo the groups now living may be said to occupy the lowest rolled over the earth since then; so we are now able to find only a matter of several hundred thousand square miles of their flat cities undestroyed-the Laurentian formations up in Canada, the oldest fossi formations known. We find that each individual animal builder was only the size of a pin-point, and that his apartment fitted his body in size. Each apartment was built upon the same plan, but they did not have the same number of rooms, showing that small and large accommodations were in demand then, just as they are now in man-made flats.

The fiat-building cousins of the first inhabitant must have undergone a kind of industrial development in which this branch of the family, without change in their bodies, acquired the art of secreting liquid lime from the water in which they lived. From this accretion they constructed their artificial stone flats. This art became an industrial family possession, to wich each member deoted a part of his time -each making his apartment in common vocation, just as the old ruilds made cloth leather, shoes or socks. This trait of animal be-
havior is called instinct. havior is called instinct.
IVe see it displayer We see it displayer
again in the building of clifferent and distinctive cocoons by the members of various tribes of moths and butterflies, in the tubes of caddis worms, and in the nests of birds.

The rhizopods were, we see, the originators of industrial brotherhoods. If we look at any of the products of som e living groups (Figs. 2, 6, 8, 9, 10) we shall find that these families were the first great users of the art of missonry, and the in ventors of mortar and stone cements. Some examples of rubble construction (Figs. 2, 9) are remarkably like such work as seen in stone fences, porch-posts and other up-to-the minute products of the human animal. When it contes to the manufacture of tine colored terra cotti (Fig. 10) with an un crackable glaze, we wil find that the workers of Some typical specimens of the rhizopods and foraminifera

possible place in the scale of creation; and he could hardly have been more highly ol-ganized, for his contemporary offspring have left us examples of thei architectural productions which show this to have been out of the question.

To speak of architectural productions in connection with animals so simple in organization as we have found the rhizopods to be seems startling to say the least; but it is a fact nevertheless that the original users of architectural structure are to be found among this family. Further than this, they were the first makers of artificial stone, which they used in construct ing the prototypes of our modern apartment buildings. They were the original cliff-dwellers; and if we glance at their flats (Fig. 1) we shill be surprised to see that they were by no means uncomfortably situated. Each little dome-topped chamber, placed in rows, and connected by oval passageways, is quite as cozy as anything that a human flat-dweller could possibly have. Many of these "flats" were 50 stories high, each story connected to its neighbors by passages.

Flat-building was rather extensively practiced in the early days, and we find that the rhizopods must have constructed them in such numbers as to have covered oractically the whole surface of the earth. That was many million years ago, and a lot of changes have these various groups have for hundreds of thousands of years been each surpassing each other in the mechinical precision and beauty of their work. Other groups (Figs. $4,5,7,11)$, not satisfied to take clay, sponge spicules, vebbles and the finished products of their cousins as building materials, construct glass and porcelain compounds. which they fashion into solid, highly-finished domiciles. (See “Nature's Geometric IVorkmen," by the present author, Scientific Amarican, December 27 th, 1919 .

What are the tools-the hands, the eyes, the brainthat enable a difflugia (Fig. 9) first to gather the transfarent quartz pebbles with which to construct its home second, to arrange the pebbles in their orderly fashion third, to hold them in place while the cement that bind them is hardening? It has been seriously suggested that man is superior to other animals only because of the shape of his hands. Here we have an extensive family of several thousand varieties, each species hav ing a tribal instinct to build a definite-shaped home, without the aid of hands, or, apparently, of any organs whatever. Each artisan uses the same material, the same ornamentation or color, the same plan and dimensions. Can anything be more confusing, not to say contradictory, of the common conception that it is brain in an animal that enables it to do these things? 